\title{
Platelet-Rich Plasma Derived Growth Factors Contribute to Stem Cell Differentiation in Musculoskeletal Regeneration
}

\author{
Yun Qian ${ }^{1,2 t}$, Qixin Han ${ }^{3 t}$, Wei Chen ${ }^{1,2 t}$, Jialin Song ${ }^{1,2}$, Xiaotian Zhao ${ }^{4}$, \\ Yuanming Ouyang ${ }^{1,2 *}$, Weien Yuan ${ }^{4 *}$ and Cunyi Fan ${ }^{1 *}$ \\ ${ }^{1}$ Department of Orthopedics, Shanghai Jiao Tong University Affiliated Sixth People's Hospital, Shanghai, China, ${ }^{2}$ Shanghai \\ Sixth People's Hospital East Campus, Shanghai University of Medicine and Health, Shanghai, China, ${ }^{3}$ Renji Hospital, School \\ of Medicine, Shanghai Jiao Tong University, Shanghai, China, ${ }^{4}$ School of Pharmacy, Shanghai Jiao Tong University, \\ Shanghai, China
}

OPEN ACCESS

Edited by: Simona Rapposelli, University of Pisa, Italy

Reviewed by:

Francesco Grassi, Istituto Ortopedico Rizzoli (IRCCS),

Italy

Dharmendra Kumar Yadav. All India Institute of Medical Sciences

Jodhpur, India

*Correspondence:

Yuanming Ouyang

ouyangyuanming@163.com

Weien Yuan

yuanweien@126.com

Cunyi Fan

cyfan@sjtu.edu.cn

${ }^{\dagger}$ These authors have contributed equally to this work.

Specialty section:

This article was submitted to

Medicinal and Pharmaceutical

Chemistry,

a section of the journal

Frontiers in Chemistry

Received: 01 July 2017 Accepted: 16 October 2017 Published: 31 October 2017

Citation:

Qian Y, Han Q, Chen W, Song J, Zhao X, Ouyang Y, Yuan W and Fan C (2017) Platelet-Rich Plasma Derived Growth Factors Contribute to Stem

Cell Differentiation in Musculoskeletal Regeneration. Front. Chem. 5:89. doi: 10.3389/fchem.2017.00089
Stem cell treatment and platelet-rich plasma (PRP) therapy are two significant issues in regenerative medicine. Stem cells such as bone marrow mesenchymal stem cells, adipose-derived stem cells and periodontal ligament stem cells can be successfully applied in the field of tissue regeneration. PRP, a natural product isolated from whole blood, can secrete multiple growth factors (GFs) for regulating physiological activities. These GFs can stimulate proliferation and differentiation of different stem cells in injury models. Therefore, combination of both agents receives wide expectations in regenerative medicine, especially in bone, cartilage and tendon repair. In this review, we thoroughly discussed the interaction and underlying mechanisms of PRP derived GFs with stem cells, and assessed their functions in cell differentiation for musculoskeletal regeneration.

Keywords: platelet-rich plasma, growth factors, stem cells, cell differentiation, musculoskeletal regeneration

\section{INTRODUCTION}

Musculoskeletal regeneration requires growing development of stem cell technology. The supply of necessary cells derived from sterile sources in physiological conditions has provided us with an unlimited and sustainable pattern in the field of cell replacement treatment and other applications (Deshpande et al., 2013). The stem cell therapy contributes to proliferative sustainability, multidirectional differentiation and anoxia endurance (Wang et al., 2016). Different tissues have been used as stem cells sources. Doctors have succeeded in making progress in many cells, such as bone marrow mesenchymal stem cells, adipose-derived stem cells and peripheral blood stem cells (Jeevanantham et al., 2012; Delewi et al., 2013). For instance, adipose-tissue derived stem cells (ADSCs) have vast therapeutic potential. On occasion, they have been applied clinically, for example, in maxillary reconstruction, critical limb ischemia or insulin-dependent diabetes mellitus. Besides, its self-renewing and differentiation in different cellular lines, including tendon and bone tissue is very important in many aspects (Ahmad et al., 2012). In vivo studies showed that mesenchymal stem cells (MSCs) can self-renew or differentiate into multiple lineages and regenerate bone, cartilage, muscle, blood, and cardiac tissue (Longo et al., 2013). They found that the transplanted cells improved the function of injured organs by attracting the host's repair cells to the damaged site by releasing certain factors (i.e., VEGF) that indirectly helped in the repair process. 
However, the exact source of these host repair cells was not fully elucidated. Besides, researchers have concentrated on the part of MSCs as an important trauma-related factor in vasculogenesis and osteogenesis (Gawlitta et al., 2012; Askarinam et al., 2013). In other words, MSC is directed to the damaged site and functions as a regulator for vasculogenesis and osteogenesis (Levi et al., 2011). Moreover, scientists believe that stem cells have huge potential in the course of cell recombination. Human stem cells can proliferate infinitely in vitro, thereby providing samples with reproducible characteristics (Thangarajah et al., 2009).

Although the therapeutic effect of stem cell is very promising, its low efficiency has compromised its potential applications in many aspects (Kang et al., 2012). People tried their best to use priming for improving the therapeutic efficacy of stem cell, but failed due to setbacks like low efficient improvement and an immune deficiency of certain proteins. Bone marrow has been identified as an excellent source of MSCs and can be accessed readily by surgeons intraoperatively. Nevertheless, scientists also attempted to obtain MSCs from fatty tissue (Angeline and Rodeo, 2012). During the last decades, scientists used a variety of different vehicles for the local delivery of MSCs, including type I collagen gels, collagen sponges and fibrin, to the Achilles, patellar, or RC tendons in animal models (Majewski et al., 2009).

In addition to stem cell therapy, blood derived products such as autologous conditioned serum and the latest orthopedic panacea, platelet rich plasma (PRP) has also been widely researched on its plentiful applications in various fields. Bone defects in the oral cavity and maxillofacial region are the major fields (Mehta, 2010); Soon later its applications extended across many fields including periodontal (Moghe et al., 2012; Morikuni et al., 2013) and oral and maxillofacial surgery (Albanese et al., 2013; Daif, 2013), aesthetic plastic surgery (Cervelli et al., 2009), spinal surgery (Okamoto et al., 2012), cardiac bypass surgery (Gravlee, 1994) and treatment of softtissue wounds or ulcers (Akhundov et al., 2012; Jiritano et al., 2013). The early introduction of PRP into clinical practice was suggested by Ferrari et al. (1987). PRP is an autologous platelet concentrate obtained from fresh whole blood by centrifugation. To be applied at the surgical site, PRP must be activated to induce platelet degranulation and fibrin polymerization, thus obtaining a clot usually called platelet gel (PG). PRP is naturally heterogeneous for various factors that exist in PRP preparation protocols including: (1) the initial quantity of platelets, (2) the applications of anticoagulants, (3) the use of leukocytes, and (4) the inclusions of activators resulting in different biological outcomes. Apart from naturally autologous state, and no risk of pathogen transmission or immunological rejection, PRP contains the appropriate proportion of certain factors necessary for wound healings (Marques et al., 2015) (referred to in Figure 1).

The biological characteristics of PRP rely on the concentration in platelets. Proper preparations can help PRP secrete many growth factors (GFs) at high concentrations, including transforming growth factor- $\beta$, platelet-derived growth factor, insulin-like growth factor, vascular endothelial growth factor and epidermal growth factor. Therefore, standardization for PRP is very important. But variation in PRP concentration usually leads to decreased and unstable repairing effect in tissue regeneration. There are a few dozens of protocols and purification systems for PRP isolation in the world. Different methods result in different PRP contents and concentrations as well as variant clinical outcomes. Most researches indicated that five times content of normal platelets can contribute to effective regeneration by PRP. And higher concentration does not induce a better result (Marx, 2004). The best concentration of PRP has not been decided yet. But different purification facilities and methods will result in different biological characteristics and variance in clinical outcomes (Yu et al., 2011). Kreuz and colleagues used different isolation kits and centrifugation for PRP preparation. The results turned out that Dr.PRP Kit could most effectively promote mesenchymal progenitor cell proliferation, compared with other methods. Moreover, some protocols could even exhibit a higher chondrogenic differentiation potential than others (Kreuz et al., 2015). Masoudi and colleagues also mentioned different modes of PRP preparation affected other aspects, like extended viability under low temperature and increased platelet yields with longer centrifugation period (Masoudi et al., 2016). Scientists have expected to combine PRP and stem cell in the field of tissue regeneration, especially bone, cartilage and tendon repair for a long time. However, the relationship between PRP preparation and stem cell activity is very controversial. There are a few important applications of PRP and stem cells in musculoskeletal regeneration in recent years. Rubio-Azpeitia and colleagues used platelet-rich plasma (PRP) three dimensional printing scaffold to induce mesenchymal stem cells differentiation, and found increased expression of collagen 1 and 3 in this model. Besides, other articular genes were upregulated as well in mesenchymal stem cells stimulated by PRP (Rubio-Azpeitia et al., 2017). Tang and colleagues experimented on rabbit derived PRP for chondrogenic induction of adiposed stem cells. Collagen II was significantly increased accompanied by aggrecan expression (Tang et al., 2015). However, Huber and colleagues discovered thrombin was effective in helping production of PRP, with an easier and faster style in comparison with other activation and purification method. However, they tested GFs like PDGF-AA, VEGF and VEGF, and found this kind of isolation method had no positive effects in promoting GFs secretion (Cares et al., 2016). PRP is vital for advancing proliferation of bone precursor cells in different animals, including rabbits and goats (Lin et al., 2013; Kim et al., 2014). In spite of rich potentials of direct applications of PRP for wound healings, combining PRP with bone marrow mesenchymal stem cells (BMSCs) for tissue regeneration applications becomes a rising interest for a long time. PRP is a significant supplement for PRP-gel delivery carrier for cell transplantation. In addition, it is mentioned that PRP can contribute to the proliferation of BMSCs and their differentiation into osteoblasts (Montgomery et al., 2011). The GFs in PRP have many functions, including accelerating angiogenesis and promoting collagen formation, thus leading to wound healing and tissue formation. Hence, PRP is thought to be an ideal origin of GFs for many applications.

According to the aspects discussed above, GFs originate from PRP and cooperate with stem cells in bone healing and soft tissue repair. This review is mainly aimed at the interaction of PRP 


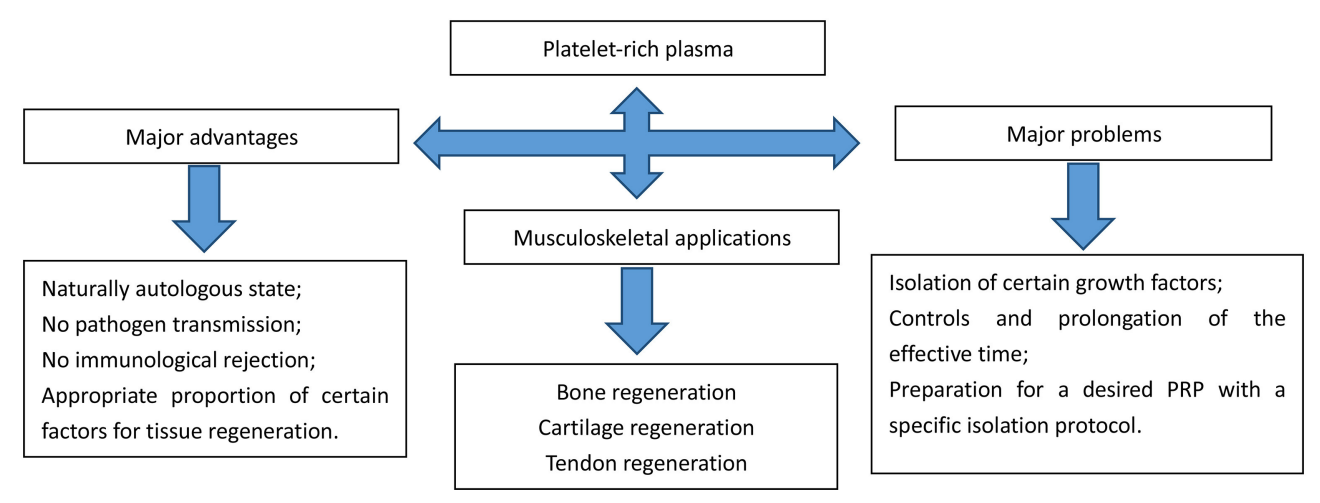

FIGURE 1 | Advantages, applications, and problems of platelet-rich plasma.

derived growth factors with stem cells in various differentiation into mature somatic cells in musculoskeletal regeneration.

\section{GROWTH FACTORS}

Growth factors derived from PRP can contribute to tissue regeneration, by assisting cell migration, proliferation, differentiation and extra-cellular matrix synthesis (Gulotta et al., 2011; Isaac et al., 2012). However, the varying GF concentrations may have different biologic effects, resulting in the fact that individual differences in GF levels should be considered for reliable interpretation of the biologic functions and standardized application of PRP. Numerous GFs, including the basic fibroblast growth factor (bFGF), platelet-derived growth factor (PDGF), and transforming growth factor- $\beta$ (TGF- $\beta$ ), which are released from PRP, can be detected during the early phase of wound healing (referred to in Table 1). Many of these GFs have a unique temporal expression profile and are thought to play an important role in the musculoskeletal regeneration. Generally, GFs are delivered locally to the bone and soft tissue regeneration site with tissue-engineered scaffolds, covered sutures, or dissolved in a fibrin-like encapsulation (Losi et al., 2013). Successful strategies to biologically augment tissue repair will require appropriate combination of GFs, responding host cells to the growth factor signaling and an optimal delivery method (Gulotta et al., 2011).

\section{Basic Fibroblast Growth Factor (bFGF)}

PRP derived basic fibroblast growth factor (bFGF) is actively involved in osteogenesis and angiogenesis. Recombinant bFGF has been used for supporting BMSCs expansion, and it is able to induce an abundant calcium deposition (Cheng et al., 2014). Preclinical researches suggest that bFGF may be useful to promote bone healing (Kawaguchi et al., 2010; Hata et al., 2013). The use of recombinant bFGF after nailing of tibial fractures significantly improves fracture healing (Granchi et al., 2013).Recently, it has been demonstrated that bFGF circulating level predicts the outcome of a severe bone lesion (Clendenen et al., 2010). Besides, polymorphonuclear neutrophils (PMN) from healthy individuals' express different levels of FGF receptors in their cytosol (FGFR-1 and FGFR-4) and cytoplasmic membrane (FGFR-2) (Chamberlain et al., 2011). These receptors may capture bFGF, therefore explaining the inverse relation between bFGF and PMN number in leukocyte platelet rich plasma (L-PRP) samples at all-time points. In addition, PRP concentrates contain lymphocytes and sustain the production of new bFGF after the initial release. The effect of leukocytes is still controversial and can be either positive or negative, depending on tissue and underlying disease. Some authors have demonstrated that the presence of PMN can result in proinflammatory cell signaling and local tissue catabolism, whereas others have shown that macrophages are essential for debridement of damaged ligamentous tissue and for cytokine release mediating the repair process (Dines et al., 2007).

\section{Insulin-Like Growth Factor 1 (IGF-1)}

IGF-1 is able to stimulate proliferation and migration of fibroblasts and other local cells, and serves as a crosslink between muscle and bone with certain physical and biochemical cues (Bikle et al., 2015). Kabiri et al. reported that the PRP has rich concentration of a few GFs like IGF-1 TGF- $\beta$ and bFGF, they also discussed its potential role in chondrogenic regeneration, especially in promoting chondrocyte proliferation and attachment as well as MSC differentiation. However, the direct role of PRP derived IGF-1 in bone and muscle regeneration is not illustrated (Kabiri et al., 2014). Creaney reported that PRP derived mechano growth factor (MGF), an isoform of IGF-1, could stimulate myoblast proliferation and it might have a potential role in improving musculoskeletal restoration. However, the short half-life limited its systemic applications. Therefore, MGF was only effective for regional use. Besides, the concentration of IGF-1 isoforms in PRP cannot sufficiently produce a promoting effect in muscle regrowth, which requires large quantification of raw material in bone and muscle repair (Creaney and Hamilton, 2008).

\section{TGF- $\beta$}

TGF- $\beta$, one of the most abundant GFs released from PRP, is demonstrated to promote tendon healing in the absence of scar formation. Therefore, it is considered as a good candidate 
TABLE 1 | Platelet-rich plasma derived Growth factors and their applications in musculoskeletal regeneration.

\begin{tabular}{|c|c|c|c|c|c|}
\hline $\begin{array}{l}\text { Growth } \\
\text { factors }\end{array}$ & tissue & $\begin{array}{l}\text { Stem } \\
\text { cells }\end{array}$ & species & functions & References \\
\hline bFGF & $\begin{array}{l}\text { bone } \\
\text { bone }\end{array}$ & $\begin{array}{l}\text { BMSC } \\
\text { BMSC }\end{array}$ & $\begin{array}{l}\text { human } \\
\text { rat }\end{array}$ & $\begin{array}{l}\text { to induce calcium deposition; to support BMSCs } \\
\text { expansion; to indicate severe bone lesion; to stimulate } \\
\text { BMSCs differentiation into bone }\end{array}$ & $\begin{array}{l}\text { Dines et al., 2007; Clendenen et al., 2010; } \\
\text { Kawaguchi et al., 2010; Hata et al., 2013; } \\
\text { Bai et al., 2014; Cheng et al., } 2014\end{array}$ \\
\hline IGF & $\begin{array}{l}\text { muscle } \\
\text { bone }\end{array}$ & PDLSC & $\begin{array}{l}\text { human } \\
\text { human }\end{array}$ & $\begin{array}{l}\text { to stimulate skeletal muscle regeneration } \\
\text { to stimulate proliferation and osteogenic differentiation }\end{array}$ & $\begin{array}{l}\text { Creaney and Hamilton, 2008; Kleplová } \\
\text { et al., 2014; Martínez et al., } 2016\end{array}$ \\
\hline TGF- $\beta$ & $\begin{array}{l}\text { bone } \\
\text { bone } \\
\text { cartilage } \\
\text { bone }\end{array}$ & $\begin{array}{l}\text { ADSC } \\
\text { ADSC } \\
\text { BMSC } \\
\text { BMSC }\end{array}$ & $\begin{array}{l}\text { human } \\
\text { rabbit } \\
\text { human } \\
\text { dog }\end{array}$ & $\begin{array}{l}\text { to stimulate bone deposition for successful fracture } \\
\text { healing; osteogenic differentiation of ADSC; } \\
\text { to stimulate chondrogenesis of BMSC; } \\
\text { to stimulate new bone formation and angiogenesis. }\end{array}$ & $\begin{array}{l}\text { Yamada et al., 2004; Zurita et al., 2010; } \\
\text { Wang et al., 2012; Busilacchi et al., 2013; } \\
\text { Elder and Thomason, } 2014\end{array}$ \\
\hline VEGF & $\begin{array}{l}\text { bone } \\
\text { bone } \\
\text { bone }\end{array}$ & $\begin{array}{l}\text { BMSC } \\
\text { BMSC } \\
\text { BMSC }\end{array}$ & $\begin{array}{l}\text { mouse/rabbit } \\
\text { rat } \\
\text { rat }\end{array}$ & $\begin{array}{l}\text { to stimulate both angiogenesis, vasculogenesis and } \\
\text { bone regeneration; } \\
\text { To increase blood flow }\end{array}$ & $\begin{array}{l}\text { Kim et al., 2010; El Backly et al., 2013; Bai } \\
\text { et al., } 2014\end{array}$ \\
\hline PDGF & $\begin{array}{l}\text { bone } \\
\text { bone } \\
\text { bone } \\
\text { tendon }\end{array}$ & $\begin{array}{l}\text { BMSC } \\
\text { BMSC } \\
\text { PDLSC } \\
\text { / }\end{array}$ & $\begin{array}{l}\text { rat } \\
\text { dog } \\
\text { human } \\
\text { human }\end{array}$ & $\begin{array}{l}\text { to promote blood vessel and bone healing; } \\
\text { to stimulate new bone formation and angiogenesis. } \\
\text { to stimulate proliferation and osteogenic differentiation; } \\
\text { to enhance tenocyte proliferation and promote synthesis } \\
\text { of ECM }\end{array}$ & $\begin{array}{l}\text { Yamada et al., 2004; Hu et al., 2009; } \\
\text { Scheibel et al., 2011; Kleplová et al., } \\
\text { 2014; Martínez et al., } 2016 .\end{array}$ \\
\hline
\end{tabular}

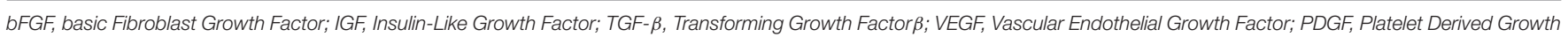
Factor; MSCs, muscle derived stem cells; BMSCs, bone marrow stem cells; ADSCs, adipose derived stem cells; PDLSCs, periodontal ligament stem cells.

to reproduce a tendon-bone insertion site. Studies about the delivery of TGF- $\beta$ at bone injury site are controversial. It was reported that high expression of TGF- $\beta$ could lead to pathologic bone formation and collagen secretion. Therefore, it resulted in abnormal fibrotic synthesis and failure of ideal bone repair (Shehata et al., 2004). Busilacchi et al. found that PRP could be regulated by synthetic materials and secrete various GFs for adipose derived stem cell differentiation. Among them, TGF- $\beta$ was obviously elevated and could stimulate bone deposition for successful fracture healing (Busilacchi et al., 2013).

\section{Vascular Endothelial Growth Factor (VEGF)}

VEGFs are a family of signaling proteins that function to stimulate both angiogenesis and vasculogenesis through a tyrosine kinase receptor-mediated signaling cascade (Kang et al., 2012). Several studies have examined VEGF augmentation of bone repairs, in different stages of bone healing, including inflammation, endochondral ossification, intramembranous ossification (Hu and Olsen, 2016). El Backly and colleagues designed a PRP based scaffold in combination with mesenchymal stem cells and they found VEGF secretion from PRP contributed to migration of endothelial cells, thus leading to angiogenesis and osteogenesis (El Backly et al., 2013). Kim used PRP for rat cranial bone defect model and discovered blood flow increase accompanied by upregulated VEGF expression in vivo (Kim et al., 2010).

\section{Platelet Derived Growth Factor (PDGF)}

Platelet-derived growth factor-BB (PDGF-BB) has been shown to improve healing in bone repair models. Recombinant PDGF can reduce osteogenic differentiation of mesenchymal cells in vitro.
Hee et al. (2011) implanted a recombinant human PDGF-BB (rhPDGF-BB) together with a type I bovine collagen matrix, in order to improve the biomechanical function and morphologic appearance of the rotator cuff repair in an ovine model. 2 weeks results showed an augmentation in biomechanical strength and anatomic appearance. Platelet derived growth factors (PDGF), could be used after a rotator cuff tear, to induce proliferation and synthesis of tenocytes with appropriate ECM proteins(Scheibel et al., 2011). In a tendon injury, the supraspinatus tenocytes are not able to synthesize normal fibrocartilaginous extracellular matrix (ECM) or collagen II, but only collagens I and III (Venneri et al., 2007). In an in vitro study, PDGFs seemed to enhance tenocyte proliferation and promote synthesis of ECM (Scheibel et al., 2011). Hu and colleagues found that PRP could upregulate VEGF and PDGF expression and stimulate BMSCs differentiation into bone $(\mathrm{Hu}$ et al., 2009).

\section{INTERACTION OF PRP DERIVED GROWTH FACTORS WITH STEM CELLS}

\section{Growth Factors and Adipose-Derived Stem Cells (ADSCs) in Musculoskeletal Regeneration}

The use of adipose-derived stem cells (ADSCs) in bone regeneration requires a sound knowledge of optimized cell isolation and handling procedures as well as culture conditions because these can significantly affect their proliferative capacity, differentiation potential and gene expression. ADSCs express surface markers likeCD44, CD73, CD90, and CD105, but are 
negative for CD14, CD34, and CD45 (Gaiba et al., 2012; Khan et al., 2012).

There are a few in vitro studies about the potential effects of PRP released GFs on stem cell and their cooperation in tissue regrowth. Wang et al. discovered that PRP could efficiently improve proliferation and differentiation of adipose derived stem cells with secretion of TGF-1 and PDGF-AB. And the effect of PRP was more long-lasting than platelet-rich fibrin (Wang et al., 2012).

Besides, the ADSCs could also be strongly induced into chondrogenic differentiation by $20 \%$ PRP derived growth factors in a cartilage alike microenvironment (Shen et al., 2015).

The combined influence of PRP derived growth factors and ADSCs was also discussed for in vivo research. Van Pham et al. noticed that activation of PRP could significantly contribute to a certain differentiation of ADSCs and improve articular cartilage regeneration in vivo (Van Pham et al., 2013).

\section{Growth Factors and Bone Marrow Derived Stem Cells (BMSCs) in Musculoskeletal Regeneration}

Mesenchymal stromal cells (MSCs) derived from a variety of sources possess the potential to be used in cell-based therapies. However, due to low proportion of primary MSCs present in bone marrowplastic adherence and in vitro expansion are essentialto proliferateBMSCs prior to clinical application.

There are a couple of important in vitro studies in this field. With the help ofchondroinductive TGF- $\beta 3$, PRP and alginate contributed equally to chondrogenic development with their own characteristics. TGF- $\beta 3$ was not a necessary factor for chondroinduction of BMSCs, but this processcould be hugely accelerated at the presence of TGF- $\beta 3$ (Zurita et al., 2010). The alginate bead culture system is indicated to greatly improve successful chondroinduction of hBMSCs in vitro, and was therefore used to compare with PRP. Those cells which do not interact with alginate molecules remain rounded shapes until a pericellular matrix is created for connections (Elder and Thomason, 2014). This spherica shape contributes todifferentiation into chondrogenic tissues. In addition, integrin dependent cell-ECM reaction stimulated by PRP can greatly improve chondrogenic differentiation stimulated by TGF- $\beta 3$. Besides, the expression of Col-2, Sox-9, and AGC could be upregulated at the presence of PRP and low TGF- $\beta 3$ expression to stimulate BMSC chondrogenic differentiation, which was possibly affected by joint efforts of various GFs from PRP in cartilage regeneration (Elder and Thomason, 2014).

In addition, the combined effect was also evaluated in some in vivo studies. The PRP of $2-5 \%$ concentration could better increase BMSC osteogenic differentiation. In this process, the expression of PDGF and TGF- $\beta$ released from PRP were greated increased, which contributed to a efficient and successful bone repair (Yamada et al., 2004). Bai et al. discovered that a joint application of VEGF and bFGF in BMSCs could significantly stimulate the osteogenesis and increased bone regeneration in a rat model. The addition of GFs could further contribute to the differentiation at the beginning of proliferation (Bai et al., 2014).

\section{Growth Factors and Periodontal Ligament Stem Cells (PDLSCs) in Musculoskeletal Regeneration}

The research on human periodontal ligament stem cells has also attracted the attention of many scientists. It is very easy to isolate the PDLSCs for its rich content from the teeth (Yeasmin et al., 2014). Moreover, the extraction and purification procedures are commonly adopted, which leads to no major harm to patients (Xiong et al., 2016).

Previous researches have reported potential impacts of PDLSCs on combination with PRP in bone regeneration in vitro, with increased ALP activity and osteogenic differentiation. Some scientists found that the ALP activity of PDLSCs increased following treatment with umbilical cord blood-platelet rich plasma (UCB-PRP) in a dose dependent manner up to a concentration of $2 \%$. ALP activity decreased with higher concentration of UCB-PRP. The effects of UCB-PRP on calcium deposition were similar to those on proliferation and ALP activity (Lee et al., 2011). Treatment with 2\% UCBPRP resulted in the highest calcium depositions in HPDLSCs. The concentrations of platelet-derived growth factor- $\mathrm{AB}$ and transforming growth factor- $\beta 1$ in UCB-PRP were investigated and found to be comparable to the amounts in peripheral blood. Besides, platelet derived growth factors isoforms (PDGFAA, PDGF-BB, PDGF-AB), Insulin-like Growth Factor Binding Proteins 2 and 6 (IGFBP-2, IGFBP-6) were also closely involved in the process. Overall, UCB-PRP had beneficial effects on the proliferation and osteogenic differentiation of human periodontal ligament stem cells (Kleplová et al., 2014). Xu and colleagues also discovered that a significant enhancement of cell differentiation in a combined use of PDLSCs and PRP. Various GFs released from PRP contributed to improved cell sheet reconstruction, elevated osteogenic gene expression, including ALP, Runx2, Col-1, and OCN. All of these results displayed a stronger periodontal tissue regenerative capacity ( $\mathrm{Xu}$ et al., 2014).

Martinez also found similar results from in vivo research. They used PRP and platelet-poor plasma in bone defect model. Increased expression of PDGF isoforms, including PDGF-AA,$\mathrm{BB}$, and $\mathrm{AB}$ as well as IGF isoforms, from both platelet concentrates could stimulate PDLSCs osteogenic stimulation and calcium deposition at a relatively low concentration (Martínez et al., 2016).

\section{CONCLUSION}

Stem cells have become more and more important in regenerative medicine and can be isolated easily and reproducibly from human tissues. They have many advantages such as easy and long-term proliferation, multi-lineage potential and tolerance toward hypoxic environments. The application of stem cells from various tissues in diverse diseases and anti-aging treatments is very promising in regenerative medicine. PRP is most often considered as a bio-aggregate of GFs and used to supplement biomaterials. It can also be prepared with fibrinogen, which can be easily activated to form fibrin gel with thrombin or calcium. 
Soon later its applications extended across many fields including periodontal and oral and maxillofacial surgery, treatment of soft-tissue wounds and so forth. Further investigation will be focused mainly on the exact signaling pathways in the interaction between genetic molecules mediated or released from GFs derived from PRP and their effects in modification, migration, and differentiation of stem cells. Primary questions lie in: (1) how to isolate certain GFs that influence a specific stem cell. We know that PRP derived growth factors can induce stem cell differentiation, proliferation and adhesion. However, a few GFs are upregulated at the same time. Therefore, it is hard to confirm the exact effecting growth factor in the process. (2) how to control and prolong the effective time of each growth factor for the best use. Normally, GFs are active under certain conditions for a short period of time. Proteins can be inactivated by many physical and chemical cues. It brings some difficulty to clinical scenario applications. (3) how to successfully prepare a desired PRP with a specific isolation protocol. There are many isolation methods with different facilities under varies temperature, humidity, and blood origin. It is hard to reach a consensus for the best PRP purification protocol. More emphasis will be laid on this aspect in preclinical and clinical researches. Once we can elucidate the underlying mechanism completely,

\section{REFERENCES}

Ahmad, Z., Wardale, J., Brooks, R., Henson, F., Noorani, A., and Rushton, N. (2012). Exploring the application of stem cells in tendon repair and regeneration. Arthroscopy 28, 1018-1029. doi: 10.1016/j.arthro.2011.12.009

Akhundov, K., Pietramaggiori, G., Waselle, L., Darwiche, S., Guerid, S., Scaletta, C., et al. (2012). Development of a cost-effective method for platelet-rich plasma (PRP) preparation for topical wound healing. Ann. Burns Fire Disasters 25, 207-213.

Albanese, A., Licata, M. E., Polizzi, B., and Campisi, G. (2013). Platelet-rich plasma (PRP) in dental and oral surgery: from the wound healing to bone regeneration. Immun. Ageing 10:23. doi: 10.1186/1742-4933-10-23

Angeline, M. E., and Rodeo, S. A. (2012). Biologics in the management of rotator cuff surgery. Clin. Sports Med. 31, 645-663. doi: 10.1016/j.csm.2012.07.003

Askarinam, A., James, A. W., Zara, J. N., Goyal, R., Corselli, M., Pan, A., et al. (2013). Human perivascular stem cells show enhanced osteogenesis and vasculogenesis with nel-like molecule I protein. Tissue Eng. A 19, 1386-1397. doi: 10.1089/ten.tea.2012.0367

Bai, Y., Leng, Y., Yin, G., Pu, X., Huang, Z., Liao, X., et al. (2014). Effects of combinations of BMP-2 with FGF-2 and/or VEGF on HUVECs angiogenesis in vitro and CAM angiogenesis in vivo. Cell Tissue Res. 356, 109-121. doi: 10.1007/s00441-013-1781-9

Bikle, D. D., Tahimic, C., Chang, W., Wang, Y., Philippou, A., and Barton, E. R. (2015). Role of IGF-I signaling in muscle bone interactions. Bone 80, 79-88. doi: 10.1016/j.bone.2015.04.036

Busilacchi, A., Gigante, A., Mattioli-Belmonte, M., Manzotti, S., and Muzzarelli, R. A. (2013). Chitosan stabilizes platelet growth factors and modulates stem cell differentiation toward tissue regeneration. Carbohydr. Polym. 98, 665-676. doi: 10.1016/j.carbpol.2013.06.044

Cares, H. S., Silmara, M., Da, S. L. Q., Urban, P. A., Lima, R. B., Duarte, L. J. F. S., et al. (2016). In vitro study of the role of thrombin in platelet rich plasma (PRP) preparation: utility for gel formation and impact in growth factors release. $J$. Stem Cells Regen. Med. 12, 2-9.

Cervelli, V., Palla, L., Pascali, M., Angelis, B. D., Curcio, B. C., and Gentile, P. (2009). Autologous platelet-rich plasma mixed with purified fat graft in aesthetic plastic surgery. Aesthetic Plast. Surg. 33, 716-721. doi: 10.1007/s00266-009-9386-0 we will illuminate the road ahead and create more miracles in musculoskeletal regeneration.

\section{AUTHOR CONTRIBUTIONS}

YQ, QH, WC, JS, XZ, YO, CF, and WY participated in its design, searched databases, extracted and assessed studies and helped to draft the manuscript. WY conceived the initial idea and the conceptualization, participated in the data extraction and analysis, and revised the manuscript. All authors read and approved the final manuscript.

\section{ACKNOWLEDGMENTS}

The study was supported by the Projects of National Science Foundation of China (No. 81373366, 81570992 and 81571261), Projects of the Shanghai Committee of Science and Technology, China (No. 12XD1403800) and Funds for Interdisciplinary Projects of Medicine and Engineering of Shanghai JiaoTong University (No. YG2015MS06, YG2014QN06 and YG2016QN22), and Science and Technology Development Foundation of Pudong New District, Shanghai, China (PKJ2016-Y55).
Chamberlain, C. S., Leiferman, E. M., Frisch, K. E., Wang, S., Yang, X., Rooijen, N. V., et al. (2011). The influence of macrophage depletion on ligament healing. Connect. Tissue Res. 52, 203-211. doi: 10.3109/03008207.2010.511355

Cheng, M. T., Liu, C. L., Chen, T. H., and Lee, O. K. (2014). Optimization of culture conditions for stem cells derived from human anterior cruciate ligament and bone marrow. Cell Transplant. 23, 791-803. doi: 10.3727/096368912X6 66430

Clendenen, T. V., Arslan, A. A., Lokshin, A. E., Idahl, A., Hallmans, G., Koenig, K. L., et al. (2010). Temporal reliability of cytokines and growth factors in EDTA plasma. BMC Res. Notes 3, 1-9. doi: 10.1186/1756-0500-3-302

Creaney, L., and Hamilton, B. (2008). Growth factor delivery methods in the management of sports injuries: state of play. Br. J. Sports Med. 42, 314-320. doi: 10.1136/bjsm.2007.040071

Daif, E. T. (2013). Effect of autologous platelet-rich plasma on bone regeneration in mandibular fractures. Dent. Traumatol. 29, 399-403. doi: 10.1111/edt.12021

Delewi, R., Andriessen, A., Tijssen, J. G. P., Zijlstra, F., Piek, J. J., and Hirsch, A. (2013). Impact of intracoronary cell therapy on left ventricular function in the setting of acute myocardial infarction: a meta-analysis of randomised controlled clinical trials. Heart 99, 225-232. doi: 10.1136/heartjnl-2012-302230

Deshpande, S., James, A. W., Blough, J., Donneys, A., Wang, S. C., Cederna, P. S., et al. (2013). Reconciling the effects of inflammatory cytokines on mesenchymal cell osteogenic differentiation. J. Surg. Res. 185, 278-285. doi: 10.1016/j.jss.2013.06.063

Dines, J. S., Grande, D. A., and Dines, D. M. (2007). Tissue engineering and rotator cuff tendon healing. J. Shoulder Elbow Surg. 16, S204-S207. doi: 10.1016/j.jse.2007.03.004

El Backly, R. M., Zaky, S. H., Muraglia, A., Tonachini, L., Brun, F., Canciani, B., et al. (2013). A platelet-rich plasma-based membrane as a periosteal substitute with enhanced osteogenic and angiogenic properties: a new concept for bone repair. Tissue Eng. A 19, 152-165. doi: 10.1089/ten.TEA.2012.0357

Elder, S., and Thomason, J. (2014). Effect of platelet-rich plasma on chondrogenic differentiation inthree-dimensional culture. Open Orthop. J. 8, 78-84. doi: $10.2174 / 1874325001408010078$

Ferrari, M., Zia, S., Valbonesi, M., Henriquet, F., Venere, G., Spagnolo, S., et al. (1987). A new technique for hemodilution, preparation of autologous plateletrich plasma and intraoperative blood salvage in cardiac surgery. Int. J. Artif. Organs. 10, 47-50. 
Gaiba, S., França, L. P., França, J. P., and Ferreira, L. M. (2012). Characterization of human adipose-derived stem cells. Acta Cir. Bras. 27, 471-476. doi: 10.1590/S0102-86502012000700007

Gawlitta, D., Fledderus, J. O., Rijen, M. H. P. V., Dokter, I., Alblas, J., Verhaar, M. C., et al. (2012). Hypoxia impedes vasculogenesis of in vitro engineered bone. Tissue Eng. A 18, 208-218. doi: 10.1089/ten.tea.2010.0731

Granchi, D., Devescovi, V., Pratelli, L., Verri, E., Magnani, M., Donzelli, O., et al. (2013). Serum levels of fibroblast growth factor 2 in children with orthopedic diseases: potential role in predicting bone healing. J. Orthopaed. Res. 31, 249-256. doi: 10.1002/jor.22219

Gravlee, G. P. (1994). Effectiveness of intraoperative autologous whole blood and platelet-rich plasma in cardiac surgery. Ann. Acad. Med. Singapore 23, 65-70.

Gulotta, L. V., Kovacevic, D., Packer, J. D., Deng, X. H., and Rodeo, S. A. (2011). Bone marrow-derived mesenchymal stem cells transduced with scleraxis improve rotator cuff healing in a rat model. Am. J. Sports Med. 39, 1282-1289. doi: $10.1177 / 0363546510395485$

Hata, Y., Ishikawa, H., Ueki, T., Kajii, T. S., Tamaoki, S., Tsuruga, E., et al. (2013). Quantitative evaluation of myofibroblast apoptosis during wound healing in rat palate after post-operative administration of basic fibroblast growth factor (bFGF). Acta Odontol. Scand. 71, 1501-1507. doi: $10.3109 / 00016357.2013 .773370$

Hee, C. K., Dines, J. S., Dines, D. M., Roden, C. M., Wisner-Lynch, L. A., Turner, A. S., et al. (2011). Augmentation of a rotator cuff suture repair using rhPDGF-BB and a type I bovine collagen matrix in an ovine model. Am. J. Sports Med. 39, 1630-1639. doi: 10.1177/0363546511404942

$\mathrm{Hu}, \mathrm{K}$., and Olsen, B. R. (2016). The roles of vascular endothelial growth factor in bone repair and regeneration. Bone 91, 30-38. doi: 10.1016/j.bone.2016.06.013

Hu, Z., Peel, S. A., Ho, S. K., Sándor, G. K., and Clokie, C. M. (2009). Platelet-rich plasma induces mRNA expression of VEGF and PDGF in rat bone marrow stromal cell differentiation. Oral Surg. Oral Med. Oral Pathol. Oral Radiol. Endod. 107, 43-48. doi: 10.1016/j.tripleo.2008.06.023

Isaac, C., Gharaibeh, B., Witt, M., Wright, V. J., and Huard, J. (2012). Biologic approaches to enhance rotator cuff healing after injury. J. Shoulder Elbow Surg. 21, 181-190. doi: 10.1016/j.jse.2011.10.004

Jeevanantham, V., Butler, M., Saad, A., Dawn, B., Abdellatif, A., and Zubasurma, E. K. (2012). Response to letter regarding article, "Adult bone marrow cell therapy improves survival and induces long-term improvement in cardiac parameters: a systematic review and meta-analysis." Circulation 126, 551-568. doi: 10.1161/CIRCULATIONAHA.111.086074

Jiritano, F., Serraino, G. F., Cristodoro, L., and Renzulli, A. (2013). Ventricular assist device abdominal driveline infection: treatment with platelet-rich plasma. J. Thorac. Cardiovasc. Surg. 145, 69-70. doi: 10.1016/j.jtcvs.2013.02.072

Kabiri, A., Esfandiari, E., Esmaeili, A., Hashemibeni, B., Pourazar, A., and Mardani, M. (2014). Platelet-rich plasma application in chondrogenesis. Adv. Biomed. Res. 3:138. doi: 10.4103/2277-9175.135156

Kang, H. J., Kim, M. K., Lee, H. Y., Park, K. W., Lee, W., Cho, Y. S., et al. (2012). Five-year results of intracoronary infusion of the mobilized peripheral blood stem cells by granulocyte colony-stimulating factor in patients with myocardial infarction. Eur. Heart J. 33, 3062-3069. doi: 10.1093/eurheartj/ehs231

Kawaguchi, H., Oka, H., Jingushi, S., Izumi, T., Fukunaga, M., Sato, K., et al. (2010). A local application of recombinant human fibroblast growth factor 2 for tibial shaft fractures: a randomized, placebo-controlled trial. J. Bone Mineral Res. 25, 2459-2467. doi: 10.1002/jbmr.146

Khan, W. S., Adesida, A. B., Tew, S. R., Longo, U. G., and Hardingham, T. E. (2012). Fat pad-derived mesenchymal stem cells as a potential source for cell-based adipose tissue repair strategies. Cell Prolif. 45, 111. doi: 10.1111/j.1365-2184.2011.00804.x

Kim, E. S., Kim, J. J., and Park, E. J. (2010). Angiogenic factor-enriched plateletrich plasma enhances in vivo bone formation around alloplastic graft material. J. Adv. Prosthodont. 2:7. doi: 10.4047/jap.2010.2.1.7

Kim, T. H., Kim, S. H., Sándor, G. K., and Kim, Y. D. (2014). Comparison of platelet-rich plasma (PRP), platelet-rich fibrin (PRF), and concentrated growth factor (CGF) in rabbit-skull defect healing. Arch. Oral Biol. 59:550. doi: 10.1016/j.archoralbio.2014.02.004

Kreuz, P. C., Krüger, J. P., Metzlaff, S., Freymann, U., Endres, M., Pruss, A., et al. (2015). Platelet-rich plasma preparation types show impact on chondrogenic differentiation, migration, and proliferation of human subchondral mesenchymal progenitor cells. Arthroscopy 31:1951. doi: 10.1016/j.arthro.2015.03.033

Lee, J. Y., Nam, H., Park, Y. J., Lee, S. J., Chung, C. P., Han, S. B., et al. (2011). The effects of platelet-rich plasma derived from human umbilical cord blood on the osteogenic differentiation of human dental stem cells. Vitro Cell. Dev. Biol. Anim. 47, 157-164. doi: 10.1007/s11626-010-9364-5

Levi, B., James, A. W., Nelson, E. R., Hu, S., Sun, N., Peng, M., et al. (2011). Studies in adipose-derived stromal cells: migration and participation in repair of cranial injury after systemic injection. Plast. Reconstr. Surg. 127, 1130-1140. doi: 10.1097/PRS.0b013e3182043712

Lin, B. N., Whu, S. W., Chen, C. H., Hsu, F. Y., Chen, J. C., Liu, H. W., et al. (2013). Bone marrow mesenchymal stem cells, platelet-rich plasma and nanohydroxyapatite-type I collagen beads were integral parts of biomimetic bone substitutes for bone regeneration. J. Tissue Eng. Regen. Med. 7, 841-854. doi: 10.1002/term.1472

Longo, U. G., Rizzello, G., Berton, A., Maltese, L., Fumo, C., Khan, W. S., et al. (2013). Biological strategies to enhance rotator cuff healing. Curr. Stem Cell Res. Ther. 8, 464-470. doi: 10.2174/1574888X113086660065

Losi, P., Briganti, E., Errico, C., Lisella, A., Sanguinetti, E., Chiellini, F., et al. (2013). Fibrin-based scaffold incorporating VEGF- and bFGF-loaded nanoparticles stimulates wound healing in diabetic mice. Acta Biomaterialia 9, 7814-7821. doi: 10.1016/j.actbio.2013.04.019

Majewski, M., Ochsner, P. E., Liu, F., Flückiger, R., and Evans, C. H. (2009). Accelerated healing of the rat Achilles tendon in response to autologous conditioned serum. Am. J. Sports Med. 37, 2117-2125. doi: 10.1177/0363546509348047

Marques, L. F., Stessuk, T., Camargo, I. C. C., Junior, N. S., Santos, L. D., and Ribeiro-Paes, J. T. (2015). Platelet-rich plasma (PRP): methodological aspects and clinical applications. Platelets 26, 101-113. doi: 10.3109/09537104.2014.881991

Martínez, C. E., González, S. A., Palma, V., and Smith, P. C. (2016). Platelet-poor and platelet-rich plasma stimulate bone lineage differentiation in periodontal ligament stem cells. J. Periodontol. 87, e18-e26. doi: 10.1902/jop.2015.150360

Marx, R. E. (2004). Platelet-rich plasma: evidence to support its use. J. Oral Maxillofac. Surg. 62, 489-496.

Masoudi, E., Ribas, J., Kaushik, G., Leijten, J., and Khademhosseini, A. (2016). Platelet-rich blood derivatives for stem cell-based tissue engineering and regeneration. Curr. Stem Cell Rep. 2, 33-42. doi: 10.1007/s40778-016-0034-8

Mehta, V. (2010). Platelet-rich plasma: a review of the science and possible clinical applications. Orthopedics 33:111. doi: 10.3928/01477447-20100104-22

Moghe, S., Saini, N., and Moghe, A. (2012). Platelet-rich plasma in periodontal defect treatment after extraction of impacted mandibular third molars. Natl. J. Maxillofac. Surg. 3, 139-143. doi: 10.4103/0975-5950.111344

Montgomery, S. R., Petrigliano, F. A., and Gamradt, S. C. (2011). Biologic augmentation of rotator cuff repair. Curr. Rev. Musculoskelet. Med. 4:221. doi: 10.1007/s12178-011-9095-6

Morikuni, T., Uysal, C. A., Xin, G., Hiko, H., and Hiroshi, M. (2013). Periodontal tissue regeneration by combined implantation of adipose tissue-derived stem cells and platelet-rich plasma in a canine model. Cytotherapy 15:1517. doi: 10.1016/j.jcyt.2013.05.007

Okamoto, S., Ikeda, T., Sawamura, K., Nagae, M., Hase, H., Mikami, Y., et al. (2012). Positive effect on bone fusion by the combination of plateletrich plasma and a gelatin $\beta$-tricalcium phosphate sponge: a study using a posterolateral fusion model of lumbar vertebrae in rats. Tissue Eng. A 18:157. doi: 10.1089/ten.tea.2011.0283

Rubio-Azpeitia, E., Sánchez, P., Delgado, D., and Andia, I. (2017). Adult cells combined with platelet-rich plasma for tendon healing: cell source options. Orthopaed. J. Sports Med. 5:2325967117690846. doi: 10.1177/2325967117690846

Scheibel, M., Schröder, R. J., Chen, J., and Bartsch, M. (2011). Arthroscopic soft tissue tenodesis versus bony fixation anchor tenodesis of the long head of the biceps tendon. Am. J. Sports Med. 39:1046. doi: 10.1177/0363546510390777

Shehata, M., Schwarzmeier, J. D., Hilgarth, M., Hubmann, R., Duechler, M., and Gisslinger, H. (2004). TGF- $\beta 1$ induces bone marrow reticulin fibrosis in hairy cell leukemia. J. Clin. Investig. 113:676. doi: 10.1172/JCI19540

Shen, J., Gao, Q., Zhang, Y., and He, Y. (2015). Autologous plateletrich plasma promotes proliferation and chondrogenic differentiation of 
adipose-derived stem cells. Mol. Med. Rep. 11:1298. doi: 10.3892/mmr. 2014.2875

Kleplová, T., Soukup, T., Reháček, V., and Suchánek, J. (2014). Human plasma and human platelet-rich plasma as a substitute for fetal calf serum during longterm cultivation of mesenchymal dental pulp stem cells. Acta Medica 57:119. doi: 10.14712/18059694.2014.50

Tang, X. B., Dong, P. L., Wang, J., Zhou, H. Y., Zhang, H. X., and Wang, S. Z. (2015). Effect of autologous platelet-rich plasma on the chondrogenic differentiation of rabbit adipose-derived stem cells in vitro. Exp. Therap. Med. 10:477. doi: 10.3892/etm.2015.2528

Thangarajah, H., Vial, I. N., Chang, E., El-Ftesi, S., Januszyk, M., Chang, E. I., et al. (2009). IFATS collection: adipose stromal cells adopt a proangiogenic phenotype under the influence of hypoxia ${ }^{\dagger \neq \$}$. Stem Cells 27:266. doi: 10.1634/stemcells.2008-0276

Van Pham, P., Bui, K. H., Ngo, D. Q., Vu, N. B., Truong, N. H., Phan, N. L., et al. (2013). Activated platelet-rich plasma improves adipose-derived stem cell transplantation efficiency in injured articular cartilage. Stem cell Res. Ther. 4:91. doi: $10.1186 /$ scrt 277

Venneri, M. A., De, P. M., Ponzoni, M., Pucci, F., Scielzo, C., Zonari, E., et al. (2007). Identification of proangiogenic TIE2-expressing monocytes (TEMs) in human peripheral blood and cancer. Blood 109:5276. doi: 10.1182/blood-2006-10-053504

Wang, M., Li, J., Liu, J., Lin, X., and Xu, W. (2012). The comparison of platelet-rich fibrin and platelet-rich plasma in releasing of growth factors and their effects on the proliferation and differentiation of adipose tissue-derived stem cells in vitro. Hua Xi Kou Qiang Yi Xue Za Zhi 30:641.

Wang, Q., Duan, F., Wang, M. X., Wang, X. D., Liu, P., and Ma, L. Z. (2016). Effect of stem cell-based therapy for ischemic stroke treatment: a meta-analysis. Clin. Neurol. Neurosurg. 146:1.

Xiong, J., Menicanin, D., Zilm, P. S., Marino, V., Bartold, P. M., and Gronthos, S. (2016). Investigation of the cell surface proteome of human periodontal ligament stem cells. Stem Cells Int. 2016, 1-13. doi: 10.1155/2016/1947157
Xu, Q., Li, B., Yuan, L., Dong, Z., Zhang, H., Wang, H., et al. (2014). Combination of platelet-rich plasma within periodontal ligament stem cell sheets enhances cell differentiation and matrix production. J. Tissue Eng. Regen. Med. 11, 627-636. doi: 10.1002/term.1953

Yamada, Y., Ueda, M., Naiki, T., Takahashi, M., Hata, K., and Nagasaka, T. (2004). Autogenous injectable bone for regeneration with mesenchymal stem cells and platelet-rich plasma: tissue-engineered bone regeneration. Tissue Eng. 10:955. doi: 10.1089/1076327041348284

Yeasmin, S., Ceccarelli, J., Vigen, M., Carrion, B., Putnam, A. J., Tarle, S. A., et al. (2014). Stem cells derived from tooth periodontal ligament enhance functional angiogenesis by endothelial cells. Tissue Eng. A 20, 1188-1196. doi: 10.1089/ten.tea.2013.0512

Yu, W., Wang, J., and Yin, J. (2011). Platelet-rich plasma: a promising product for treatment of peripheral nerve regeneration after nerve injury. Int. J. Neurosci. 121, 176-180. doi: 10.3109/00207454.2010.544432

Zurita, M., Otero, L., Aguayo, C., Bonilla, C., Ferreira, E., Parajón, A., et al. (2010). Cell therapy for spinal cord repair: optimization of biologic scaffolds for survival and neural differentiation of human bone marrow stromal cells. Cytotherapy 12, 522-537. doi: 10.3109/14653241003 615164

Conflict of Interest Statement: The authors declare that the research was conducted in the absence of any commercial or financial relationships that could be construed as a potential conflict of interest.

Copyright (c) 2017 Qian, Han, Chen, Song, Zhao, Ouyang, Yuan and Fan. This is an open-access article distributed under the terms of the Creative Commons Attribution License (CC BY). The use, distribution or reproduction in other forums is permitted, provided the original author(s) or licensor are credited and that the original publication in this journal is cited, in accordance with accepted academic practice. No use, distribution or reproduction is permitted which does not comply with these terms. 